\title{
Growth Rate of Kappaphycus striatum var cottonii at Different Positions of the Cultivation Lines to the Direction of Water Current
}

\author{
Cherry Nian ${ }^{1,2}$, Jainal Akrim ${ }^{1,2}$, Didang Shara Jumah ${ }^{1}$ and Rafsanjani Samimi ${ }^{1}$ \\ 1. Aquaculture Department, College of Fisheries, Mindanao State University-Tawi-Tawi College of Technology and Oceanography \\ Sanga-Sanga, Bongao, Tawi-Tawi, 7500 Philippines \\ 2. Multi-Species Hatchery, College of Fisheries, Mindanao State University-Tawi-Tawi College of Technology and Oceanography \\ Sanga-Sanga, Bongao, Tawi-Tawi, 7500 Philippines
}

\begin{abstract}
The study was conducted to determine the effects of different positions in cultivation lines towards the direction of water current on growth rate of Kappaphycus striatum var. cottonii for a duration of $45 \mathrm{~d}$ at $4^{\circ} 30^{\prime} 9.36^{\prime \prime} \mathrm{N}$ and $119^{\circ} 22^{\prime} 6.8^{\prime \prime} \mathrm{E}$ of Bungin Pondohan, Sitangkai, Tawi-Tawi. The experiment has three treatments; the parallel (T1), perpendicular (T2) and diagonal (T3) positions towards the direction of water current with five replicates in each treatment following the randomized complete block design (RCBD). Results showed that higher mean weight of $473 \mathrm{~g}$ and growth increment of $8.3 \mathrm{~g} / \mathrm{d}$ were obtained from T3, although not significantly different from T1 and T2 with $431 \mathrm{~g}$ and $7.4 \mathrm{~g} / \mathrm{d}$, and $408 \mathrm{~g}$ and $6.8 \mathrm{~g} / \mathrm{d}$, respectively $(p>0.05)$. However, results showed statistically similar growth rates of $K$. striatum var cottonii among all treatments. Thus, the positions of cultivation lines with respect to the direction of the current have no significant effect on the growth of the said seaweed species. Hence, the treatments used are viable in growing K. striatum var. cottonii in the selected study site.
\end{abstract}

Key words: Cultivation, diagonal, Kappaphycus striatum var cottonii, parallel, perpendicular.

\section{Introduction}

Seaweeds have been utilized in many places of the world for millennia especially in Asia. The benefits traditionally ascribed to marine plants have stimulated the development of seaweed aquaculture. One of the major sources of livelihood for Filipinos for so many years already is the seaweed farming. At present, the seaweed industry offers a wide range of compounds [1] to meet the increasing demands of the textile, cosmetics and food sectors. Seaweed products are of particular importance in the food industry [2] which utilizes them as components of fertilizers, in animal feed supplements [3] and as additives for human food [4]. Industrially cultivated seaweed now supplies more

Corresponding author: Cherry Nian, assistant professor, research field: aquaculture specifically in seaweed, finfish and shellfish production. than $90 \%$ of the algae marketed internationally $[5,6]$. Seaweeds represent an important source of the polysaccharides (agar, alginates and carrageenan) used in the pharmaceutical as well as the food industries [3, 7]. Thus, the increasing world population will clearly require additional food sources in the near future. The chemical and nutritional composition of marine seaweeds depends on many factors [8], including species, geographical origin or area of cultivation, seasonal, environmental and physiological variations [7], time of harvest, water temperature and processing methods. It is now emerging to be an important and major livelihood in the coastal areas, especially in the Southern Philippines, wherein two major culture methods are used by the farmers, namely the fixed bottom monoline and floating method monoline. These methods are usually done parallel to the current direction. As for any type of farming, the supply of 
nutrients is an essential factor for growing crops. Therefore, water movement is considered as an important factor for seaweeds growth. Thus, there is a need for an improvement of cultivation strategy that enables the farmer to increase their production.

This study evaluates the effects of the different positions of cultivation line (parallel, perpendicular and diagonal) to the direction of the water current on the growth of Kappaphycus striatum var. cottonii seedlings. The specific objective was to determine the most applicable position of cultivation line to the direction of the water current that will enable the farmers to achieve highest growth and yield of seaweed Kappaphycus.

\section{Materials and Methods}

\subsection{Site and Duration of the Study}

The study was conducted at the coastal area of Bungin Pondohan, Sitangkai, Tawi-Tawi, for a culture period of $45 \mathrm{~d}$ from December 25, 2013 to February 8, 2014. The growth performance of Kappaphycus seedlings was evaluated using three (3) different positions of cultivation lines to the direction of water current: the parallel (T1), perpendicular (T2) and diagonal (T3) with five replicates in each treatment following the randomized complete block design (RCBD).

\subsection{Preparation and Construction of the Farm}

Prior to planting, the farm was cleaned of grazers, herbivorous animals and other competitors. After cleaning, holes were made in the substratum using pointed iron bar. Wooden pegs were firmly driven into the holes at $3 \mathrm{~m}$ apart. The stakes were installed and arranged as cultivation lines were tied and stretched in three different positions to the direction of the water current. All cultivation lines were tightly stretched below the lowest tide level and two feet above the substratum by tying both ends to the opposite wooden stakes.

\subsection{Collection and Transport of Seedlings}

The Kappaphycus seedlings were procured from seaweed farm near the study site and placed inside a styrofoam box covered with wet sack to avoid direct exposure from sunlight and transported immediately using a motorized boat. While on transport, the seedlings were sprinkled frequently with fresh seawater to avoid stress. Best quality and healthy seed stocks were selected for planting that possess the following characteristics: heavily pigmented thallus; brittle, shiny and slimy branches; young branches with sharp pointed tips and no traces of grazing and "ice-ice" [9]. Upon arrival at the farm, all transported seed stocks were immediately immersed in seawater inside the seedling bin to avoid mortality and to allow them to recover from handling stress.

\subsection{Preparation and Planting of Seedlings}

The seed stocks were cleaned of sediments, weeds, epiphytes and live animals (i.e., shells, sponges, soft corals, etc.) and other foreign materials. After cleaning, they were cut into desired weight (100 g) for planting using a clean sharp stainless steel knife to leave smooth surfaces. The seaweed cuttings were tied to $350 \mathrm{~cm}$ monoline using soft plastic tying material or soft plastic straw at $1.5 \mathrm{~cm}$ interval between bunches. In each line has 20 bunches. After completely tying the seedlings, those were brought to the farm and directly tied to the cultivation lines. The seedlings were planted without delay to avoid mortality. The initial mass weight of the seedlings in every cultivation line were taken and recorded.

\subsection{Sampling and Monitoring of Water Parameters}

The seedlings were sampled for growth and production parameters at $15 \mathrm{~d}$ interval. The cultivation lines were untied from the stakes one by one. The crop plants were thoroughly cleaned of silts, epiphytes and other foreign materials before taking and recording their mass weight. Weighing scale was used to weigh 
the seedlings. When weighing was completed, the cultivation lines were immediately retied to the respective stakes where they were originally tied to avoid stress. Water salinity and temperature were also recorded using refractometer and thermometer, respectively.

\subsection{Farm Maintenance}

To ensure good growth and minimize losses of cultivated seaweed, the farm were visited regularly to monitor changes in the environmental factors; remove sediments and other particles by shaking the cultivation lines; remove weeds, epiphytes and live animals from the cultivation lines and seedlings; prepare and replace weak and damage farm support structure and prune or cut the thallus infected by "ice-ice" disease.

\subsection{Harvest and Data Analysis}

The experiment was done after $45 \mathrm{~d}$ of culture. An inventory of the seed stock was conducted at late in the afternoon of the last day of planting. The seaweeds were harvested line by line starting from the cultivation line number one and continued until all seed stocks were completely harvested. The harvested seaweeds were thoroughly cleaned of sediments, weeds, epiphytes and live animals before taking their final mass weight in each cultivation line to avoid biased in data recording.
The growth data will be calculated as follows:

Growth rate:

$$
\begin{gathered}
M W G=W f-W i \\
D G I=W f-W i / t \\
D G R=[(\log W f-\log W i) / t] \times 100
\end{gathered}
$$

where $M W G=$ mean weight gain, $D G I=$ daily growth increment, $D G R=$ daily growth rate, $W i=$ initial weight, $W f=$ final weight, $t=$ time of culture in days.

A single factor analysis of variance (ANOVA) was used to test the significance of the effects of the different treatments at $\alpha=0.05$.

\section{Results and Discussion}

The results are presented in Table 1. Kappaphycus seedlings planted at different positions of cultivation lines to the direction of water current were not significantly different among treatments. Highest mean final weight $(\mathrm{FW})$, weight gain (WG), daily growth increment (DGI) and daily growth rate (DGR) were obtained from treatment 3 (diagonal) with $473 \mathrm{~g}$, $373 \mathrm{~g}, 8.3 \mathrm{~g} / \mathrm{d}$ and $1.5 \%$ than treatment 1 (parallel) with $431 \mathrm{~g}, 331 \mathrm{~g}, 7.4 \mathrm{~g} / \mathrm{d}$ and $1.41 \%$ and treatment 2 (perpendicular) with $408 \mathrm{~g}, 308 \mathrm{~g}, 6.8 \mathrm{~g} / \mathrm{d}$ and $1.36 \%$ $(p>0.05)$, respectively. Results also revealed that the water salinity and temperature are ranging from 34-35 ppt and $29-30{ }^{\circ} \mathrm{C}$, respectively (Table 2 ).

Seaweed farmers faced a problem on low production because most of the nutrients in the water column are not utilized or not well-distributed. In general,

Table 1 Final weight, weight gain, daily growth increment (DGI) (g) and daily growth rate (DGR) of Kappaphycus striatum var. cottonii seedlings after $45 \mathrm{~d}$ of culture.

\begin{tabular}{llllll}
\hline Treatment & Initial weight $(\mathrm{g})$ & Final weight $(\mathrm{g})$ & Weight gain $(\mathrm{g})$ & DGI $(\mathrm{g})$ & DGR $(\%)$ \\
\hline Parallel (T1) & 100 & $431^{\mathrm{a}}$ & $331^{\mathrm{a}}$ & $7.4^{\mathrm{a}}$ & $1.41^{\mathrm{a}}$ \\
Perpendicular (T2) & 100 & $408^{\mathrm{a}}$ & $308^{\mathrm{a}}$ & $6.8^{\mathrm{a}}$ & $1.36^{\mathrm{a}}$ \\
Diagonal (T3) & 100 & $473^{\mathrm{a}}$ & $373^{\mathrm{a}}$ & $8.3^{\mathrm{a}}$ & $1.5^{\mathrm{a}}$ \\
\hline Mian
\end{tabular}

Means in the same column sharing the same letters in superscript are not significantly different $(p>0.05)$.

Table 2 The salinity and temperature of the farm site every sampling.

\begin{tabular}{lll}
\hline Date & Salinity $(\mathrm{ppt})$ & Temperature $\left({ }^{\circ} \mathrm{C}\right)$ \\
\hline December 25, 2013 & 34 & 29 \\
January 9, 2014 & 34 & 30 \\
January 24, 2014 & 35 & 30 \\
February 8, 2014 & 34 & 29 \\
\hline
\end{tabular}


farmers use longline method that runs horizontally on the water surface. This method utilizes only one position towards the water current thus productivity is still low, while other positions to the water current have nutrients that still have the potential to support the growth of seaweed. Few improvements in farming techniques have been made since its first introduction [10]. Seaweed cultivation system is still leading to improve its quality and production. Water derived from deeper waters is rich in nutrients that can be utilized as culture and cultivation media for various types of seaweed [11] as it carries by the water movements like currents. Different methods of Eucheuma farming from the past were attempted from simple bottom culture to the more refined types using some form of a support system, such as the raft method, fixed off-bottom (net) method, tubular net method and fixed off bottom monoline method [12]. However, the different positions of the cultivation lines to the direction of water current using fixed bottom method in the present study resulted in statistically similar growth performance of $K$. striatum var. cottonii. This DGR of $K$. striatum var. cottonii had similar results to the previous studies which had obtained rates of $1.1 \%-3.4 \%$ [13], $0.2 \%-4.2 \%$ [14] and $1.1 \%-5.3 \%$ [15]. The off-bottom method is used to overcome pest problems, but can be done only on sandy soils where stakes can be plugged [16]. With this method, a very high farming with intensity in terms of seedlings per area unit can be achieved. The shortcoming however is the relatively close distance to the sea bottom that do not receive optimum light levels [17] during high tide and times of turbidity spills and benthic herbivores still might reach the plants, e.g., by climbing up the poles or benthic structures below farms [18]. The very shallow waters are also the natural habitat of herbivorous fishes (mainly of the families Acanthuridae, Scaridae and Siganidae), which can cause total crop loss [19].

Water temperature and salinity of the present study had a comparable range of the previous study with
$27.67-30.72{ }^{\circ} \mathrm{C}$ and $24 \%$ - $30 \%$, respectively [20] that were within the required levels for eucheumoid cultivation [21].

\section{Conclusions}

Diagonal positions of $K$. striatum var. cottonii cultivation lines to the direction of water current exhibited statistically similar growth performance to parallel and perpendicular positions. Therefore, the positions of the seaweed cultivation lines to the direction of water current showed no significant effect on the growth performance of $K$. striatum var. cottonii and these results will be used as basis for seaweed cultivation.

\section{Acknowledgments}

The authors are grateful to the College of Fisheries, Mindanao State University-Tawi-Tawi College of Technology and Oceanography for research funding and providing also a scholarship to Ms. Didang Shara U. Jumah.

\section{References}

[1] Buschmann, A. H., Correa, J. A., Westermeier, R., Hernandez-Gonzalez, M., and Norambuena, R. 2001. "Red Algal Farming in Chile: A Review." Aquaculture 194 (3-4): 203-20.

[2] Jensen, A. 1993. "Present and Future Needs for Algae and Algal Products." Hydrobiology 260 (1): 15-23.

[3] Indergaard, M., and Minsaas, J. 1991. "Animal and Human Nutrition." In Seaweed Resources in Europe: Uses and Potential, edited by Guiry, M. D., and Blunden G. John Wiley \& Sons, New York, 21-64.

[4] Jiménez-Escrig, A., and Goñi-Cambrodón, I. 1999. "Nutritional Evaluation and Physiological Effects of Edible Marine Macroalgae." Arch. Latinoam. Nutr. 49: 114-20. (in Spanish)

[5] Griffin, N. J., Bolton, J. J., and Anderson, R. J. 1999. "The Effects of a Simulated Harvest on Porphyra in South Africa." Hydrobiology 398: 183-9.

[6] Chopin, T. 1999. "Water Aquaculture of the Red Algae Chondrus crispus in Prince Edward Island, Canada." Hydrobiology 399: 417-25.

[7] Mabeau, S., and Fleurence, J. 1993. "Seaweed in Food Products: Biochemical and Nutritional Aspects." Trends Food Sci. Technol. 4: 103-7. 

Lines to the Direction of Water Current

[8] El-Said, G. F., and El-Sikaily, A. 2013. "Chemical Composition of Some Seaweed from Mediterranean Sea Coast, Egypt." Environ. Monit. Assess. 185 (7): 6089-99.

[9] Hurtado, A. Q., Critchley, A. T., and Bleicher-L'Honneur, G. 2008a. Kappaphycus cottonii Farming, revised ed. Degussa Texturizing Solutions, Baupte, France.

[10] Hurtado, A. Q., Gerung, G. S., Yasir, S., and Critchley, A. T. 2014. "Cultivation of Tropical Red Seaweeds in the BIMP-EAGA Region.” J. Appl. Phycol. 26: 707-18.

[11] Sahoo, D., and Ohno, M. 2003. "Culture of Kappaphycus alvarezii in Deep Seawater and Nitrogen Enriched Medium.” Bull. Mar. Sci. Fish. Kochi Univ. 22: 89-96.

[12] Johnson, B., and Gopakumar, G. 2011. "Farming of the Seaweed Kappaphycus alvarezii in Tamil Nadu Coast -Status and Constraints." Marine Fisheries Information Service T\&E Ser. 208: 1-5.

[13] Hurtado-Ponce, A. 1995. "Carrageenan Properties and Proximate Composition of Three Morphotypes of Kappaphycus alvarezii Doty (Gigartinales, Rhodophyta)." Botanica Marina. 38: 215-9.

[14] Hurtado, A., Agbayani, R., Sanares, R., and Castro-Mallare, M. 2001. "The Seasonality and Economic Feasibility of Cultivating Kappaphycus alvarezii in Panagatan Cays, Caluya, Antique, Philippines." Aquaculture 199: 295-310.

[15] de Góes, H., and Reis, R. 2012. "Temporal Variation of the Growth, Carrageenan Yield and Quality of Kappaphycus alvarezii (Rhodophyta, Gigartinales) Cultivated at Sepetiba Bay, Southeastern Brazilian Coast.”
J. Appl. Phycol. 24: 173-80.

[16] Rejeki, S., Ariyati, R. W., Widowati, L. L., and Bosma, R. H. 2018. "The Effect of Three Cultivation Methods and Two Seedling Types on Growth, Agar Content and Gel Strength of Gracilaria verrucosa." Egyptian Journal of Aquatic Research 44 (1): 65-70.

[17] Indriatmoko, Heriyanto, Limantara, L., and Brotosudarmo, T. H. P. 2015. "Composition of Photosynthetic Pigments in a Red Alga Kappaphycus alvarezii Cultivated in Different Depths." Procedia Chemistry 14: 193-201.

[18] Blankenhorn, S. U. 2007. "Seaweed Farming and Artisanal Fisheries in an Indonesian Seagrass Bed-Complementary or Competitive Usages?" Ph.D. thesis, University Bremen.

[19] Tomas, F., Romero, J., and Turon, X. 2005. "Experimental Evidence That Intra-specific Competition in Seagrass Meadows Reduces Reproductive Potential in the Sea Urchin Paracentrotus lividus (Lamarck)." Scientia Marina. 69: 475-84.

[20] Orbita, M. L. S. 2013. "Growth Rate and Carrageenan Yield of Kappaphycus alvarezii (Rhodophyta, Gigartinales) Cultivated in Kolambogan, Lanao Del Norte, Mindanao, Philippines." A. A. B. Bioflux 5 (3): 128-39.

[21] Hurtado, A., Critchley, A., and Trespoey, A. $2008 \mathrm{~b}$. "Growth and Carrageenan Quality of Kappaphycus striatum var. sacol Grown at Different Stocking Densities, Duration of Culture and Depth." J. Appl. Phycol. 20: 551-5. 